Received September 17; accepted November 8, 1975

1 Hewitt, E. J., A. Rev. Pl. Physiol., 26, 73-100 (1975)

2 Lafferty, M. A., and Garrett, R. H.,J.biol. Chem., 249, 7555-7567(1974).

Downey, R. J., Biochem. Biophys. Res. Commun, 50,920-925 (1973).

Rosso, J. P., Forget, P., and Pinchinoty, F., Biochim. biophys. Acta, 321, 443-445 (1973)

Bowen, A. R., and Taube, H., J. Am. chem. Soc., 93, 3287-3289 (1971).

Kustin, K., and Toppen, D., Inorg. Chem., 11, 2851-2852(1972).

Sasaki, Y., and Sykes, A. G., J. chem. Soc., Dalton Trans., 1048-1054 (1975).

Bowen, A. R., and Taube, H., Inorg. Chem., 13, 2245-2249 (1974).

Nicholas, D. J. D., and Stevens, H. M., Nature, 176, 1066-1067 (1955)

Massey, V., Brumby, P. E., Komai, H., and Palmer, G., J. biol. Chem., 244, $1682-1691$ (1969).

1 Shilov, A., et al., Nature, 231, 460-461 (1971).

Ardon, M., and Pernick, A., Inorg. Chem., 12, 2484-2485 (1973).

Guymon, E. P., and Spence, J. T., J. phys. Chem., Wash. 70, 1964-1969 (1966).

Nason, A., and Evans, H. J., J. biol. Chem., 202, 655-673 (1953).

Frank, J. A., and Spence, J. T., J. phys. Chem., Wash. 68, 2131-2135 (1964)

6 Forget, P., and DerVartanian, D. V., Biochim. biophys. Acta, 256, 600-606 (1972).

Garner, C. D. Hyde, M. R., Mabbs, F. E., and Routledge, V. I., Nature, 252, 579-580 (1974).

18 Garner, C. D., Hyde, M. R., and Mabbs, F. E., Nature, 253, 623-625(1975).

Garner, C. D., Hyde, M. R., Mabbs, F. E., and Routledge, V. I., J. chem. Soc., Dalton Trans., 12, 1180-1186(1975)

Williams, R. J. P., Trans. biochem. Soc., 1, 1-26(1973)

1 Nicholas D. J. D and Nason, A J biol Chem 211, 183-197(1954).

22 Garrett, R. H., and Nason, A.,J.biol. Chem., 244, 2870-2882 (1969).

\section{Relevance of oxygen ligands to reduction of ligating dinitrogen}

WE have reported ${ }^{1}$ the reduction of dinitrogen, in cis- $\left[\mathrm{M}\left(\mathrm{N}_{2}\right)_{2^{-}}\right.$ $\left.\left(\mathrm{PMe}_{2} \mathrm{Ph}\right)_{4}\right]$ ( $A$, where $\mathrm{M}=\mathrm{Mo}$ or $\left.\mathrm{W}\right)$, to ammonia, on treatment with sulphuric acid in methanol at $20^{\circ} \mathrm{C}$. The reaction of the molybdenum complex is complete in $3-4 \mathrm{~min}$ but the yield ( $\leqslant 0.8 \mathrm{~mol}$ per Mo atom) is only about half that from the tungsten complex ( $\leqslant 1.8 \mathrm{~mol}$ per $\mathrm{W}$ atom), which requires about $0.5 \mathrm{~h}$ for complete reaction. We now find that ammonia is produced almost equally well, $(1.7 \mathrm{~mol}$ per $\mathrm{W}$ atom), but much more slowly, from a methanol solution of $A$, (with $\mathrm{M}=\mathrm{W}$ ) either at the boil (3-4 h) or on irradiation for $30 \mathrm{~h}$ at $20^{\circ} \mathrm{C}(2 \times 150-\mathrm{W}$ tungsten filament lamps $)$; a boiling ethanol solution yields only 0.4 mol $\mathrm{NH}_{3}$ per $\mathrm{W}$ atom. In contrast, $A$, (with $\mathrm{M}=\mathrm{Mo}$ ) gives very little ammonia (only $0.08 \mathrm{~mol}$ per Mo at best) in any of the above conditions; instead it evolves dinitrogen and dihydrogen.

It is not clear why the molybdenum complex produces so little ammonia from its reaction with methanol alone, in contrast to both its reaction in presence of sulphuric acid and the reactions of its tungsten analogue. One dinitrogen molecule is rapidly lost in all reactions of $A,(\mathrm{M}=\mathrm{W}$ or $\mathrm{Mo})$ leading to some intermediate which, in accord with the general chemistry of molybdenum and tungsten, should probably be more labile in the molybdenum series.

This greater lability may account for a more ready loss of the second dinitrogen ligand from molybdenum and the generally lower yields of ammonia. The greater lability may also be particularly damaging when the intermediate is a methanol- or methoxo-hydrido complex in boiling methanol rather than a sulphato- or other oxo-anion complex at $20^{\circ} \mathrm{C}$. It is, however, possible that the tungsten and molybdenum complexes yield ammonia by different chemical mechanisms ${ }^{2}$.

In both the tungsten and the molybdenum series of complexes, the protonation of $\mathrm{N}_{2}$ to $\mathrm{NH}_{3}$ in good yield seems to depend on the replacement of the tertiary phosphine ligands by ligands ligating through oxygen (for example, $\mathrm{OH}^{-}, \mathrm{SO}_{4}{ }^{2-}, \mathrm{MeOH}$ ). All are replaced from the tungsten complexes, but perhaps only two from the molybdenum. Sulphate is the most effective oxo-anion tried, but others, including phosphate, are almost as good. Chloride and bromide are less effective (our unpublished results).

The importance of ligating oxygen probably lies in its effectiveness as a $\pi$-electron donor to early transition metals especially in higher oxidation states. The progressive replacement of the first dinitrogen molecule, which is a strong $\pi$ acceptor, and the tertiary phosphine ligands (weak or neutral $\pi$-acceptors) by the $\pi$-donor oxygen ligands progressively raises the d-electron energy levels on the metal atom, so that electrons pass from the metal to the second dinitrogen molecule as its protonation proceeds; possibly by a mechanism outlined in ref. 2. Chloride and bromide are less effective as $\pi$ donors and so lend themselves to the isolation of complexes containing dinitrogen in intermediate stages of reduction ${ }^{2}$.

Oxygen ligands are undoubtedly important in promoting the protonation and reduction of ligating dinitrogen to hydrazine or ammonia in suitable early transition metal (groups IV to VI) complexes. Whenever reasonable yields (for example, $>0.1 \mathrm{~mol}$ $\mathrm{N}_{2} \mathrm{H}_{4}$ or $>0.2 \mathrm{~mol} \mathrm{NH}_{3}$ per transition metal atom) of nitrogen hydrides have been obtained by protonation of a dinitrogen complex, an oxygen ligand, or an oxygen-containing solvent, such as hydroxide ${ }^{3}$, catechol ${ }^{3}$, ether ${ }^{4}$, methanol-sulphuric acid ${ }^{1}$, propylene carbonate or $N$-methylpyrrolidone ${ }^{5}$, has been involved.

This observation raises the question as to whether, in nitrogenase, the molybdenum, assumed to be the active site, is in an oxygen environment. Chemical evidence seems to point in that direction because almost quantitative yields of hydrazine have been obtained from dinitrogen by its reaction with $\mathrm{V}(\mathrm{OH})_{2}$ either in aqueous alkaline suspension or in solution with catechol ${ }^{3}$. This demonstrates that molecular nitrogen can interact with early transition metal ions in oxidation states accessible in aqueous solution, and presumably also in other oxygen or oxygen-nitrogen environments such as may ligate molybdendum in the enzyme.

\section{Joseph CHATt}

Alan J. Pearman

RAYMOND L. RICHARDS

Unit of Nitrogen Fixation,

University of Sussex,

Brighton BN1 9QJ, UK

Received October 6; accepted December 5, 1975.

1 Chatt, J., Pearman, A. J., and Richards, R. L., Nature, 253, 39 (1975). Chatt, J., Pearman, A. J., and Richards, R. L., I. Organomental. Chem., 101, C45 (1975)

${ }^{3}$ Shilov, A. E., Russ. Chem. Rev., 43, 5 (1974).

4 Manriquez, J. M., and Bercaw, J. E., J. Am. Chem. Soc., 96, 6229 (1974).

5 Brulet, C. R., and van Tamelen, E. E., J. Am. Chem. Soc., 97, 911 (1975).

\section{Elevation of selenium}

\section{levels in air by xerography}

Rooms in which xerography machines are used for document reproduction frequently have a strong, characteristic 'selenium' smell. It seemed likely that this is caused by selenium compounds released from the selenium plates or drums charged with high voltages in the photosensitising step of the photoelectric printing process. To test this hypothesis, we sampled the air in an unventilated room (48 $\mathrm{m}^{3}$ in volume) housing a xerographic machine, on which some 450-475 copies were reproduced in intermittent use daily. The air was drawn by a small sampling pump at a rate of 1 foot $^{3} \mathrm{~h}^{-1}$ through a fritted diffuser into $20 \mathrm{ml}$ of $0.1 \mathrm{~N} \mathrm{NaOH}$ for $9 \mathrm{~h} \mathrm{~d}^{-1}$ for $4 \mathrm{~d}$. The selenium trapped $(0.005-0.015 \mu \mathrm{g})$ was determined according to the fluorimetric method of Olson ${ }^{1}$.

Values obtained in replicate runs lay between 20 and $60 \mathrm{ng}$ of selenium (as Se) per $\mathrm{m}^{3}$ of air. The variation in levels may be ascribed to differences in the number of copies made and the non-compliance of users of the machine with a request to keep the door of the room closed during the sampling periods.

The levels found were thus invariably much higher than the $1.2 \mathrm{ng} \mathrm{m}^{3}$ measured in the San Francisco Bay area ${ }^{2}$, a level already considered to be elevated 2,400 times beyond the natural background accountable for in terms of soil and seawater contents. Average levels of $0.9 \mathrm{ng} \mathrm{m}^{-3} \mathrm{Se}$ were found in seven air samples taken in the Cambridge, Massachusetts area ${ }^{3}$.

Selenium is an essential trace element for bacteria and animals, and probably also for plants ${ }^{4}$; however, there seems to be a rather narrow range of beneficial selenium availability. Below certain levels, signs of selenium deficiency occur and at somewhat higher levels, signs of 